\title{
A Neanderthal OAS1 isoform Protects Against COVID-19 Susceptibility and Severity: Results from Mendelian Randomization and Case-Control Studies
}

Sirui Zhou ${ }^{1,2},{ }^{*}$ Guillaume Butler-Laporte ${ }^{1,2},{ }^{*}$ Tomoko Nakanishi ${ }^{1,3,4,5},{ }^{*}$ David Morrison ${ }^{1}$, Jonathan Afilalo ${ }^{1}$, Marc Afilalo ${ }^{1}$, Laetitia Laurent ${ }^{1}$, Maik Pietzner ${ }^{6}$, Nicola Kerrison ${ }^{6}$, Kaiqiong Zhao ${ }^{1,2}$, Elsa BrunetRatnasingham ${ }^{7}$, Danielle Henry ${ }^{1}$, Nofar Kimchi ${ }^{1}$, Zaman Afrasiabi ${ }^{1}$, Nardin Rezk ${ }^{1}$, Meriem Bouab ${ }^{1}$, Louis Petitjean, ${ }^{1}$ Charlotte Guzman ${ }^{1}$, Xiaoqing Xue ${ }^{1}$, Chris Tselios, ${ }^{1}$ Branka Vulesevic ${ }^{1}$, Olumide Adeleye ${ }^{1}$, Tala Abdullah ${ }^{1}$, Noor Almamlouk ${ }^{1}$, Yiheng Chen ${ }^{1}$, Michaël Chassé ${ }^{7}$, Madeleine Durand ${ }^{7}$, Michael Pollak ${ }^{1}$, Clare Paterson ${ }^{8}$, Hugo Zeberg ${ }^{9}$, Johan Normark ${ }^{10}$, Robert Frithiof ${ }^{11}$, Miklós Lipcsey ${ }^{12,13}$, Michael Hultström ${ }^{11,13}$, Celia M T Greenwood ${ }^{1,2}$, Claudia Langenberg 6,14 , Elin Thysell ${ }^{15}$, Vincent Mooser ${ }^{3}$, Vincenzo Forgetta ${ }^{1}$, Daniel E. Kaufmann ${ }^{7,16}$, J Brent Richards ${ }^{1,2,3,17}$

\section{Affiliations:}

1) Lady Davis Institute, Jewish General Hospital, McGill University, Montréal, Québec, Canada

2) Department of Epidemiology, Biostatistics and Occupational Health, McGill University, Montréal, Québec, Canada

3) Department of Human Genetics, McGill University Montréal, Québec, Canada

4) Kyoto-McGill International Collaborative School in Genomic Medicine, Graduate School of Medicine, Kyoto University, Kyoto, Japan

5) Research Fellow, Japan Society for the Promotion of Science

6) MRC Epidemiology Unit, University of Cambridge School of Clinical Medicine, Cambridge, UK

7) Division of Infectious Diseases and Research Centre of the Centre Hospitalier de l'Université de Montréal, Montréal, Canada

8) SomaLogic, Inc., Boulder, Colorado, USA

9) Department of Neuroscience, Karolinska Institutet, Stockholm, Sweden

10) Molecular Infection Medicine Sweden (MIMS), Umeå University

11) Anaesthesiology and Intensive Care Medicine, Department of Surgical Sciences, Uppsala University, Uppsala, Sweden.

12) Hedenstierna Laboratory, CIRRUS, Anaesthesiology and Intensive Care Medicine, Department of Surgical Sciences, Uppsala University, Uppsala, Sweden

13) Integrative Physiology, Department of Medical Cell Biology, Uppsala University, Uppsala, Sweden

14) Computational Medicine, Berlin Institute of Health, Charité University Medicine Berlin, Germany

15) Department of Medical Biosciences, Umeå University

16) Department of Medicine, Université de Montréal, Montréal, Canada

17) Department of Twin Research, King's College London, London, United Kingdom

\section{*These authors contributed equally to this study}

\section{Corresponding author:}

Brent Richards, Professor of Medicine, McGill University

Senior Lecturer, King's College London (Honorary)

Pavilion H-413, Jewish General Hospital

3755 Côte-Ste-Catherine Montréal, Québec, Canada, H3T 1E2

$\mathrm{T}:+15143408222 \times 24362 \quad \mathrm{~F}:+15143407529$

E: brent.richards@mcgill.ca $\quad$ www.mcgill.ca/genepi

Funding: The Richards research group is supported by the Canadian Institutes of Health Research (CIHR: 365825; 409511), the Lady Davis Institute of the Jewish General Hospital, the Canadian Foundation for Innovation (CFI), the NIH Foundation, Cancer Research UK, Genome Québec, the Public Health Agency of Canada, the McGill Interdisciplinary Initiative in Infection and Immunity and the Fonds de Recherche 
medRxiv preprint doi: https://doi.org/10.1101/2020.10.13.20212092; this version posted December 24, 2020. The copyright holder for this preprint (which was not certified by peer review) is the author/funder, who has granted medRxiv a license to display the preprint in perpetuity.

It is made available under a CC-BY-NC-ND 4.0 International license .

56

57

58

59

60

61

62

63

64

65

66

67

68

69

70

71

72

73

74
Québec Santé (FRQS). SZ is supported by a CIHR fellowship and a FRQS fellowship. GBL is supported by the a CIHR scholarship, and a joint FRQS and Québec Ministry of Health and Social Services scholarship. TN is supported by Research Fellowships of Japan Society for the Promotion of Science (JSPS) for Young Scientists. JBR is supported by a FRQS Clinical Research Scholarship. Support from Calcul Québec and Compute Canada is acknowledged. TwinsUK is funded by the Welcome Trust, Medical Research Council, European Union, the National Institute for Health Research (NIHR)-funded BioResource, Clinical Research Facility and Biomedical Research Centre based at Guy's and St Thomas' NHS Foundation Trust in partnership with King's College London. BQC-19 is funded by FRQS, Genome Québec and the Public Health Agency of Canada. These funding agencies had no role in the design, implementation or interpretation of this study. VM is supported by a Canada Excellence Research Chair. The Kaufmann lab COVID-19 work is supported by the CIHR/CITF (VR2-173203), AmFAR (110068-68RGCV) the CFI and FRQS. RF is supported by Swedish Research Council (2014-02569 and 2014-07606). $\mathrm{MH}$ is supported by a SciLifeLab/KAW national COVID-19 research program project grant (KAW 2020.0182).

Disclosures: JBR has served as an advisor to GlaxoSmithKline and Deerfield Capital.

Key words: Genome-wide association studies, COVID-19, Mendelian randomization, proteomics 
medRxiv preprint doi: https://doi.org/10.1101/2020.10.13.20212092; this version posted December 24, 2020. The copyright holder for this preprint (which was not certified by peer review) is the author/funder, who has granted medRxiv a license to display the preprint in perpetuity.

It is made available under a CC-BY-NC-ND 4.0 International license .

75

76

77

78

79

80

81

82

83

84

85

86

87

88

89

90

91

92

93

94

\begin{abstract}
Proteins detectable in peripheral blood may influence COVID-19 susceptibility or severity. However, understanding which circulating proteins are etiologically involved is difficult because their levels may be influenced by COVID-19 itself and are also subject to confounding factors. To identify circulating proteins influencing COVID-19 susceptibility and severity we undertook a large-scale two-sample Mendelian randomization (MR) study, since this study design can rapidly scan hundreds of circulating proteins and reduces bias due to reverse causation and confounding. We identified genetic determinants of 931 circulating proteins in 28,461 SARS-CoV-2 uninfected individuals, retaining only single nucleotide polymorphism near the gene encoding the circulating protein. We found that a standard deviation increase in OAS1 levels was associated with reduced COVID-19 death or ventilation ( $N=4,336$ cases / 623,902 controls; $\left.\mathrm{OR}=0.54, \mathrm{P}=7 \times 10^{-8}\right)$, COVID-19 hospitalization $(\mathrm{N}=6,406 / 902,088 ; \mathrm{OR}=0.61, \mathrm{P}=$ $\left.8 \times 10^{-8}\right)$ and COVID-19 susceptibility $\left(N=14,134 / 1,284,876\right.$; $\left.O R=0.78, P=8 \times 10^{-6}\right)$. Results were consistent in multiple sensitivity analyses. We then measured OAS1 levels in 504 patients with repeated plasma samples ( $\mathrm{N}=1039)$ with different COVID-19 outcomes and found that increased OAS1 levels in a non-infectious state were associated with protection against very severe COVID-19, hospitalization and susceptibility. Further analyses suggested that a Neanderthal isoform of OAS1 affords this protection. Thus, evidence from MR and a case-control study supported a protective role for OAS1 in COVID-19 outcomes. Available medicines, such as phosphodiesterase-12 inhibitors, increase OAS1 and could be explored for their effect on COVID-19 susceptibility and severity.
\end{abstract}


medRxiv preprint doi: https://doi.org/10.1101/2020.10.13.20212092; this version posted December 24, 2020. The copyright holder for this preprint (which was not certified by peer review) is the author/funder, who has granted medRxiv a license to display the preprint in perpetuity.

It is made available under a CC-BY-NC-ND 4.0 International license .

95

96

97

98

99

100

\section{1}

102

103

104

105

106

107

108

109

110

111

112

113

114

115

116

117

118

119

120

\section{Introduction}

To date, the COVID-19 pandemic has caused more than 1.6 million deaths worldwide, and infected over 75 million individuals. ${ }^{1}$ Despite the scale of the epidemic, there are at present few disease-specific therapies ${ }^{2}$. to reduce the morbidity and mortality of SARS-CoV-2 infection, and apart from dexamethasone therapy in oxygen dependent patients ${ }^{3}$, most clinical trials have shown at most mild or inconsistent benefits in disease outcome. ${ }^{4-6}$ Therefore, validated targets are needed for COVID-19 therapeutic development.

One source of such targets is circulating proteins. Recent advances in large-scale proteomics have enabled the measurement of thousands of circulating proteins at once and when combined with evidence from human genetics, such targets greatly improve the probability of drug development success. ${ }^{7-9}$ While de novo drug development will take time-even in the accelerated arena of COVID-19 therapiesrepurposing of currently available molecules targeting those proteins could also provide an accelerated opportunity to deliver new therapies to patients.

Nevertheless, since confounding and reverse causation often bias traditional circulating protein epidemiological studies, disentangling the causal relationship between circulating proteins and COVID-19 susceptibility or severity is challenging. This is especially the case in COVID-19, where exposure to SARS-CoV-2 unleashes profound changes in circulating protein levels ${ }^{10}$. One way to address these limitations is by using Mendelian randomization (MR), a genetic epidemiology method that uses genetic variants as instrumental variables to test the effect of an exposure (here protein levels) on an outcome (here COVID-19 outcomes). Given that genotypes are determined by randomly segregated alleles during meiosis of parental gametes, this greatly reduces bias due to confounding. Since genotypes are always assigned prior to disease onset, MR studies are not influenced by reverse causation. However, MR rests on several assumptions ${ }^{11}$, the most problematic being the lack of horizontal pleiotropy of the genetic instruments (wherein the genotype influences the outcome, independently of the exposure). One way to 
medRxiv preprint doi: https://doi.org/10.1101/2020.10.13.20212092; this version posted December 24, 2020. The copyright holder for this preprint (which was not certified by peer review) is the author/funder, who has granted medRxiv a license to display the preprint in perpetuity.

It is made available under a CC-BY-NC-ND 4.0 International license .

121 help avoid this bias is to use genetic variants that influence circulating protein levels which are adjacent to

122 the gene which encodes the circulating protein through the use of cis-protein quantitative trait loci (cis-

123 pQTLs). ${ }^{9}$ Given their close proximity to the target gene, cis-pQTLs are likely to influence the level of the

124 circulating protein, among others, by directly influencing its transcription or translation, and therefore less

125 likely to affect the outcome of interest (COVID-19) through pleiotropic pathways. Nevertheless, a causal

126 genetic association between the exposure and outcome may be confounded by linkage disequilibrium

127 (LD, the non-random association of genetic variants assigned at conception). ${ }^{12}$ To probe this potential

128 problem, colocalization tests can assess for the presence of bias from LD.

130 Understanding the etiologic role of circulating proteins in infectious diseases is challenging because the

131 infection itself often leads to large changes in circulating protein levels ${ }^{10}$. Thus, it may appear that an

132 increase in a circulating protein, such as a cytokine, is associated with a worsened outcome, when in fact,

133 the cytokine may be the host's response to this infection and help to mitigate this outcome. It is therefore

134 important to identify genetic determinants of the protein levels in the non-infected state, which would

135 reflect a person's baseline predisposition to the level of a protein.

137 MR studies can be complemented by traditional case-control studies, where the protein is longitudinally measured in COVID-19 patients and controls, allowing for an estimation of the association between the

139 protein level and COVID-19 outcomes. However, MR studies would tend to predict the effect of the 140 protein in the non-infectious state when the genetic determinants of such proteins are measured in the

141 non-infected population. Thus, longitudinal measurements of proteins can allow for a better

142 understanding of the role of such proteins in COVID-19 outcomes and also describe how their levels

143 respond to the infection. Since MR and case-control studies rely on different assumptions, and may be

144 influenced by different biases, concordant results between the two study designs can strengthen the

145 cumulative evidence through the concept of the triangulation of evidence ${ }^{13}$. 
medRxiv preprint doi: https://doi.org/10.1101/2020.10.13.20212092; this version posted December $24,2020$. The copyright holder for this preprint (which was not certified by peer review) is the author/funder, who has granted medRxiv a license to display the preprint in perpetuity.

It is made available under a CC-BY-NC-ND 4.0 International license .

147 In this study, we therefore undertook two-sample MR and colocalization analyses to combine results from

148 large-scale genome-wide association studies (GWAS) of circulating protein levels and COVID-19

149 outcomes ${ }^{14}$ in order to prioritize proteins likely influencing COVID-19 outcomes. We began by identifying

150 the genetic determinants of circulating protein levels in large-scale protein level GWASs, then used MR to

151 assess whether these cis-pQTLs were associated with COVID-19 outcomes in the ICDA Host Genetics

152 Initiative COVID-19 outcomes GWASs. Next, we investigated expression QTL (eQTL) and splice QTL

153 (sQTL) effects of our lead proteins. We then measured the most promising protein, OAS1, in 504 subjects

154 ascertained for SARS-CoV-2 infection and when PCR positive, followed for longitudinal sampling during

155 and after their infection.

157 Results

158 MR using cis-pQTLs, and pleiotropy assessment

159 Study design is illustrated in Figure 1. We began by obtaining the genetic determinants of circulating 160 protein levels from six large proteomic GWAS of European individuals (Sun et a/15 $\mathrm{N}=3,301$; Emilsson et $161 a^{16} \mathrm{~N}=3,200$; Pietzner et a/17 $\mathrm{N}=10,708$; Folkersen et all8 $\mathrm{N}=3,394$; Yao et al ${ }^{19} \mathrm{~N}=6,861$ and Suhre et aR0

$162 \mathrm{~N}=997)$. A total of 931 proteins from these six studies had cis-pQTLs associated at a genome-wide 163 significant level $\left(P<5 \times 10^{-8}\right)$ with protein levels, or highly correlated proxies (LD $\left.R^{2}>0.8\right)$, in the meta164 analyses of data the from COVID-19 Host Genetics Initiative ${ }^{21}$ which included results from the

165 GenOMICC program ${ }^{22}$. We then undertook MR analyses using 1,425 directly matched cis-pQTLs and 39

166 proxies as genetic instruments across six studies for their associated circulating proteins on three

167 separate COVID-19 outcomes: 1) Very severe COVID-19 disease (defined as individuals experiencing

168 death, mechanical ventilation, non-invasive ventilation, high-flow oxygen, or use of extracorporeal

169 membrane oxygenation. 99.7\% of these individuals were of European ancestry) using 4,336 cases and

170623,902 controls; 2) COVID-19 disease requiring hospitalization using 6,406 cases and 902,088 controls

171 of European ancestry and 3) COVID-19 susceptibility using 14,134 cases and 1,284,876 controls of

172 European ancestry. These case-control phenotype definitions are referred to as A2, B2, and C2 by the

173 COVID-19 Host Genetics Initiative, respectively. In all outcomes, cases required evidence of SARS-CoV- 
medRxiv preprint doi: https://doi.org/10.1101/2020.10.13.20212092; this version posted December 24, 2020. The copyright holder for this preprint (which was not certified by peer review) is the author/funder, who has granted medRxiv a license to display the preprint in perpetuity.

It is made available under a CC-BY-NC-ND 4.0 International license .

1742 infection. For the very severe COVID-19 and hospitalization outcomes, COVID-19 cases were defined

175 as laboratory confirmed SARS-CoV-2 infection based on nucleic acid amplification or serology tests. For

176 the COVID-19 susceptibility outcome, cases were also identified by review of health records (using

177 International Classification of Disease codes or physician notes).

MR analyses revealed that the levels of three circulating proteins, 2'-5'-oligoadenylate synthetase 1

180 (OAS1), interleukin-10 receptor beta subunit (IL10RB) and ABO were associated with at least two COVID-19 outcomes after Benjamini \& Hochberg FDR correction for the number of proteins tested (Table 1, Tables S1-6). We note that FDR correction is overly conservative given the non-independence of the circulating protein levels. Notably, increased OAS1 levels were strongly associated with protection from all three COVID-19 outcomes. Further, these effect sizes were more pronounced in severe and hospitalization outcomes, such that each standard deviation increase in OAS1 levels was associated with decreased odds of very severe COVID-19 (OR=0.54; 95\% Cl: $\left.0.44-0.68, P=7.0 \times 10^{-8}\right)$, hospitalization $\left(\mathrm{OR}=0.61 ; 95 \% \mathrm{Cl}: 0.51-0.73, \mathrm{P}=8.3 \times 10^{-8}\right)$ and susceptibility (OR=0.78; 95\% $\left.\mathrm{Cl}: 0.69-0.87, \mathrm{P}=7.6 \times 10^{-6}\right)$

(Figure 2A). We also identified OAS1 cis-pQTLs in Emilsson et a/l6 and Pietzner et a/17 which were not included in the MR analyses due to lack of genome-wide significance in their association with OAS1 levels or missing from initial protein panel. Undertaking MR analyses of using these additional cis-pQTLs, we found concordant results (Table S7).

We next assessed whether the cis-pQTL associated with OAS1 levels (rs4767027) was associated with any other phenotypes across more than 5,000 outcomes, as catalogued in PhenoScanner, ${ }^{23}$ which 195 collects associations of SNPs with outcomes from all available GWASs. We found that the only significant 196 association for rs4767027 was with circulating OAS1 levels $\left(P=6.2 \times 10^{-26}\right)$ in plasma, whereas it was not 197 associated with any other traits or protein levels $\left(P<5.0 \times 10^{-5}\right)$. These findings reduce the possibility that 198 the MR estimate of the effect of OAS1 on COVID-19 outcomes is due to horizontal pleiotropy. Finally, 199 except for the susceptibility outcome, the effect of rs4767027 did not demonstrate evidence of 200 heterogeneity across COVID-19 Host Genetics Initiative GWAS meta-analyses (Table 1). 
medRxiv preprint doi: https://doi.org/10.1101/2020.10.13.20212092; this version posted December 24, 2020. The copyright holder for this preprint (which was not certified by peer review) is the author/funder, who has granted medRxiv a license to display the preprint in perpetuity.

It is made available under a CC-BY-NC-ND 4.0 International license .

202 We next identified an independent SNP associated with OAS1 circulating protein levels, which was not at 203 the OAS1 locus and is thus a trans-SNP (rs62143197, $\mathrm{P}$ value for association with OAS1 levels $=7.10 \mathrm{x}$ $\left.20410^{-21}\right)$. However, this SNP is likely subject to pleiotropic effects, since it is strongly associated with many 205 other proteins, such as annexin A2 ( $\left.P=5.6 \times 10^{-237}\right)$ and small ubiquitin-related modifier $3\left(P=9.1 \times 10^{-178}\right)$. 206 Consequently, including this trans-SNP could introduce bias from horizontal pleiotropic effects and was 207 thus not considered in further MR analyses. Further, this trans-association signal was unique to the 208 INTERVAL study ${ }^{17}$.

OAS proteins are part of the innate immune response against RNA viruses. They are induced by interferons and activate latent RNase L, resulting in direct viral and endogenous RNA destruction, as demonstrated in in-vitro studies. ${ }^{24}$ Thus OAS1 has a plausible biological activity against SARS-CoV-2.

214 Using a cis-pQTL for IL10RB (rs2834167), we found that one standard deviation increase in circulating 215 IL10RB level was associated with decreased odds for very severe COVID-19 (OR=0.47; 95\% Cl: $0.32-$ $\left.2160.68, \mathrm{P}=7.1 \times 10^{-5}\right)$ and hospitalization $\left(\mathrm{OR}=0.53 ; 95 \% \mathrm{Cl}: 0.39-0.73, \mathrm{P}=8.8 \times 10^{-5}\right)$. However, circulating 217 IL10RB protein level was not associated with COVID-19 susceptibility. Using PhenoScanner, we could 218 not find evidence of pleiotropic effects of the cis-pQTL for IL10RB. The IL10RB cis-pQTL also showed a 219 homogeneous effect across the three COVID-19 outcomes except for susceptibility to COVID-19 (Table

220 1, Figure 2A). MR revealed that one standard deviation increase in circulating $A B O$ level was associated 221 with increased odds of adverse COVID-19 outcomes (Table 1), however, we found that a cis-pQTL for 222 ABO (rs505922) was strongly associated with the levels of several other proteins, suggesting potential 223 horizontal pleiotropic effects (Table S8). Given ABO's known involvement in multiple physiological 224 processes, these results were expected, but highlight that MR analyses may suffer from significant bias 225 from horizontal pleiotropy. 
medRxiv preprint doi: https://doi.org/10.1101/2020.10.13.20212092; this version posted December 24, 2020. The copyright holder for this preprint (which was not certified by peer review) is the author/funder, who has granted medRxiv a license to display the preprint in perpetuity.

It is made available under a CC-BY-NC-ND 4.0 International license .

\section{Colocalization Studies}

228 To test whether confounding due to LD may have influenced the estimated effect of circulating OAS1 on

229 the three different COVID-19 outcomes, we tested the probability that the genetic determinants of OAS1

230 circulating protein level were shared with the three COVID-19 outcomes using colocalization analyses.

231 These were performed using coloc, a Bayesian statistical test implemented in the coloc R package. ${ }^{12}$ We

232 found that the posterior probability that OAS1 levels and COVID-19 outcomes shared a single causal

233 signal (the posterior probability for hypothesis 4 in coloc, PP4) in the 1Mb locus around the cis-pQTL

234 rs4767027 was 0.72 for very severe COVID-19, 0.82 for hospitalization due to COVID-19, and 0.89 for

235 COVID-19 susceptibility (Figure 3). This colocalization result was also replicated using cis-pQTLs for

236 OAS1 levels identified by Pietzner et a ${ }^{17}$ (Table S7). This suggests that there is likely a single shared

237 causal signal for OAS1 circulating protein levels and COVID-19 outcomes.

Colocalization of $\mathrm{ABO}$ levels and different COVID-19 outcomes also showed colocalization between ABO level and different COVID-19 outcomes (posterior probability of single shared signal $=0.90,0.98$ and 1 for ABO level and very severe COVID-19, hospitalization due to COVID-19 and susceptibility, respectively) (Figure S1). We were unable to perform colocalization analyses for IL10RB due to a lack of genome-wide summary level data from the original proteomic GWAS ${ }^{16}$.

\section{Aptamer Binding Effects}

246 Protein altering variants (PAVs) ${ }^{15}$ may influence binding of affinity agents, such as aptamers or

247 antibodies, that are used to quantify protein levels. We thus assessed if the cis-pQTLs for the MR-

248 prioritized proteins were PAVs, or in LD $\left(R^{2}>0.8\right)$ with PAVs, and if so, whether conditioning the cis-

249 pQTLs on correlated PAVs influenced their association with COVID-19 outcomes. rs2834167 (IL10RB) is

250 a nonsense variant and could therefore be subject to potential binding effects. rs505922 (ABO) is not in

251 LD with known missense variants. rs4767027 (OAS1) is an intronic variant, which is in LD with a

252 missense variant rs2660 $\left(R^{2}=1\right)$ in European ancestry. Unfortunately, this missense variant was not 
medRxiv preprint doi: https://doi.org/10.1101/2020.10.13.20212092; this version posted December 24, 2020. The copyright holder for this preprint (which was not certified by peer review) is the author/funder, who has granted medRxiv a license to display the preprint in perpetuity.

It is made available under a CC-BY-NC-ND 4.0 International license .

253 included in the imputation data of Sun et al, and the effect by this missense variant could not be

254 evaluated. However, since RNA splicing and expression studies derived from RNA sequencing are not

255 subject to potential effects of missense variants that could influence aptamer binding, we next explored

256 whether rs4767027 also influences OAS1 splicing and/or expression.

sQTL and eQTL studies for OAS genes

259 Splicing QTLs (sQTLs) are genetic variants that influence the transcription of different isoforms of a

260 protein. The aptamer that targets OAS1 was developed against a synthetic protein comprising the amino

261 acid sequence 1-364 of NP002525.225, which is common to the two major OAS1 isoforms, p46 and p42,

262 and hence the aptamer may identify both, or either isoforms. rs10774671 is a known sQTL for OAS1 that

263 induces alternate splicing and create p46 and p42, a majority of present-day people carry this splice

264 variant (rs10774671-A), which increases expression of isoforms other than $p 46^{26}$. The ancestral variant

265 (rs10774671-G) is the major allele in African populations and became fixed in Neanderthal and

266 Denisovan genomes 27,28 . However, the ancestral variant, with its increased expression of the p46 isoform,

267 was reintroduced into the European population via gene flow from Neanderthals ${ }^{29}$, and is also the

268 predominant isoform found in circulating blood 26 . The $p 46$ isoform has been demonstrated to have higher

269 anti-viral activity than other isoforms ${ }^{30}$. Interestingly, the OAS1 pQTL, rs4767027, is in high LD $\left(R^{2}=0.97\right)$

270 with rs1077467129 in European populations. Functional studies support that the G allele at rs 10774671

271 increases expression of the p46 isoform but decreases expression of the $p 42$ isoform ${ }^{26}$. This $G$ allele at

272 the sQTL rs10774671 reflects the T allele at PQTL rs4767027, which itself is associated with higher

273 measured OAS1 levels and reduced odds of COVID-19 severity and susceptibility. These separate lines

274 of evidence suggest that the p46 isoform was predominantly measured by the SomaScan ${ }^{\circledR}$ platform and

275 may protect against COVID-19 outcomes.

277 Undertaking MR studies of OAS1 splicing, we found that increased expression of the p46 isoform (as 278 defined by normalized read counts of the intron cluster defined by LeafCutter ${ }^{31,32}$ ) was associated with 
medRxiv preprint doi: https://doi.org/10.1101/2020.10.13.20212092; this version posted December 24, 2020. The copyright holder for this preprint (which was not certified by peer review) is the author/funder, who has granted medRxiv a license to display the preprint in perpetuity.

It is made available under a CC-BY-NC-ND 4.0 International license .

279

280

281

282

283

284

285

286

287

288

289

290

291

292

293

294

295

296

297

298

reduced odds of COVID-19 outcomes $\left(\mathrm{OR}=0.29 ; 95 \% \mathrm{Cl}: 0.17-0.49, \mathrm{P}=4.1 \times 10^{-6}\right.$ for susceptibility, $\mathrm{OR}=$ $0.09 ; 95 \% \mathrm{Cl}: 0.04-0.21, \mathrm{P}=2.0 \times 10^{-8}$ for hospitalization and $\mathrm{OR}=0.05 ; 95 \% \mathrm{Cl}: 0.02-0.13, \mathrm{P}=3.1 \times 10^{-9}$ for very severe COVID-19) (Figure 2B). Colocalization analyses also supported a shared causal signal between the SQTL for OAS1, the pQTL and COVID-19 outcomes (Figure S2A-B). Interestingly, the colocalization analyses supported a stronger probability of a shared signal with the sQTL, than the pQTL, suggesting that the p46 isoform may be the driver of the association of OAS1 levels with COVID-19 outcomes.

Next, we tested whether increased expression of OAS1 levels, without respect to isoform, were associated with COVID-19 outcomes using eQTL MR analyses. We identified an expression QTL (eQTL) for total OAS1, rs10744785, from GTEx v8. ${ }^{33}$ Total OAS1 expression levels were not associated with COVID-19 susceptibility and hospitalization (Figure 2B). We also found that increased OAS3 expression level in whole blood was positively associated with COVID-19 outcomes in MR analyses with a support for colocalization of their genetic signal (Table S9, Figure S3).

Taken together, these pQTL, sQTL and eQTL studies suggest that increased levels of the p46 isoform of OAS1 protect against COVID-19 adverse outcomes. Further, the concordant evidence from sQTL and pQTL MR studies suggest that the effect of OAS1 levels on COVID-19 outcomes is unlikely to be biased by aptamer binding effects.

\section{Association of measured OAS1 protein level with COVID-19 outcomes}

Since MR studies were derived from protein levels measured in a non-infected state, we tested the hypothesis that increased OAS1 protein levels in a non-infected state would be associated with reduced odds of COVID-19 outcomes. To do so, we undertook a case-control study, measuring OAS1 protein levels using the SomaScan ${ }^{\circledR}$ platform in 1039 longitudinal samples from 399 SARS-CoV-2 PCR positive patients collected at multiple time points during their COVID-19 infection and 105 individuals who 
medRxiv preprint doi: https://doi.org/10.1101/2020.10.13.20212092; this version posted December 24, 2020. The copyright holder for this preprint (which was not certified by peer review) is the author/funder, who has granted medRxiv a license to display the preprint in perpetuity.

It is made available under a CC-BY-NC-ND 4.0 International license .

305

306

307

308

309

310

311

312

313

314

315

316

317

318

319

320

321

322

323

324

325

326

327

328

329

330

331

presented with COVID-19 symptoms but had negative SARS-CoV-2 PCR nasal swabs from the Biobanque Quebecoise de la COVID-19 cohort (www.BQC19.ca). Individuals were recruited prospectively who had undergone nasal swabs for SARS-CoV-2 infection. The demographic characteristics of the participants in the BQC19 cohort who underwent SomaScan ${ }^{\circledR}$ assays is detailed in Table 2.

We defined non-infectious samples as those collected from convalescent SARS-CoV-2 patients at least 31 days after onset of their symptoms $(\mathrm{N}=115)$, or samples collected from SARS-CoV-2 PCR negative patients $(\mathrm{N}=105)$. These SARS-CoV-2 PCR negative patients were recruited as controls into the study, as their inclusion reduces the probability of the introduction of collider bias ${ }^{34}$. As we also observed a change in OAS1 level with the exposure to the SARS-CoV-2 virus (Figure S4), in order to understand how OAS1 protein levels during infection would be associated with COVID-19 outcomes, we also measured OAS1 levels in individuals with samples from SARS-CoV-2 positive patients $<14$ days after symptom onset $(\mathrm{N}=313)$. Sample outliers were removed (Figure S5, S6), and we showed that OAS1 levels are not associated with age and sex in samples without active infection (Figure S7). Additional sample QC and characterization of the cohort is described in Supplementary data.

To test whether OAS1 levels in a non-infectious state were associated with COVID-19 outcomes we undertook logistic regression using the three COVID-19 outcomes, while controlling for age, sex, age ${ }^{2}$, plate, recruitment center and sample processing time. OAS1 levels were log-transformed and standardized to match the transformation procedure of the MR study. We found that in the non-infectious samples, each standard deviation increase in OAS1 levels on the log-transformed scale was associated with reduced odds of COVID-19 outcomes $(\mathrm{OR}=0.20$ [95\% Cl: $0.08-0.53] ; \mathrm{P}=0.001$ for very severe COVID-19, OR $=0.46[95 \% \mathrm{Cl}: 0.28-0.76], \mathrm{P}=0.002$ for hospitalization and $\mathrm{OR}=0.69[95 \% \mathrm{Cl}: 0.49-$ 0.98], $P=0.04$ for susceptibility) (Figure 4, Table S10, Figure S8). These results are consistent with our findings from MR, where increased circulating OAS1 levels in a non-infectious state were associated with protection against all of these adverse COVID-19 outcomes. 
medRxiv preprint doi: https://doi.org/10.1101/2020.10.13.20212092; this version posted December $24,2020$. The copyright holder for this preprint (which was not certified by peer review) is the author/funder, who has granted medRxiv a license to display the preprint in perpetuity.

It is made available under a CC-BY-NC-ND 4.0 International license .

333 In samples drawn during active infection we found that increased OAS1 levels were associated with 334 increased odds of adverse COVID-19 outcomes (OR $=1.49$ [95\% Cl: $1.19-1.90]$; $\mathrm{P}=0.0007$ for very

335 severe COVID-19, OR $=1.92[95 \% \mathrm{Cl}: 1.46-2.56], \mathrm{P}=4.8 \times 10^{-6}$ for hospitalization and $\mathrm{OR}=4.39[95 \%$

$336 \mathrm{Cl}: 2.87-6.73], \mathrm{P}=1.09 \times 10^{-11}$ for susceptibility) (Figure 4, Table S10, Figure S8).

Taken together, these findings suggest that increased OAS1 levels in a non-infectious state are associated with better COVID-19 outcomes, and that during infection, SARS-CoV-2 exposure likely causes OAS1 levels to increase, as interferon pathways are stimulated, which are known to increase OAS1 levels 35 .

\section{Discussion:}

Disease-specific therapies are needed to reduce the morbidity and mortality associated with COVID-19 outcomes. In this large-scale two-sample MR study of 931 proteins assessed for three COVID-19 outcomes in up to 14,134 cases and 1.2 million controls with European ancestry, we provide evidence

347 that increased OAS1 levels in the non-infectious state are strongly associated with reduced risks of very 348 severe COVID-19, hospitalization and susceptibility. The protective effect size was particularly large, such 349 that a $50 \%$ decrease in the odds of very severe COVID-19 was observed per standard deviation increase 350 in OAS1 circulating levels. Since therapies exist that activate OAS1, repositioning them as potential 351 COVID-19 treatments should be prioritized.

353 In non-Sub-Saharan African populations, the protective alleles at both rs4767027-T (the OAS1 pQTL) and 354 rs10774671-G (the OAS1 sQTL) are found on a Neandertal haplotype which was passed on to modern 355 humans $\sim 50-60,000$ years $a^{30}{ }^{36}$. Even though these two SNPs share a haplotype, their evolutionary 356 histories differ. The rs4767027-T allele is derived from the Neandertal lineage, whereas for the 357 rs 10774671-G allele, Neanderthals preserved the ancestral state. OAS1 alternative splicing regulated by 
medRxiv preprint doi: https://doi.org/10.1101/2020.10.13.20212092; this version posted December 24, 2020. The copyright holder for this preprint (which was not certified by peer review) is the author/funder, who has granted medRxiv a license to display the preprint in perpetuity.

It is made available under a CC-BY-NC-ND 4.0 International license .

358

359

360

361

362

363

364

365

366

367

368

369

370

371

372

373

374

375

376

377

378

379

380

381

382

383

the rs $10774671-\mathrm{G}$ allele increases the isoform p46, which is known to have a higher enzymatic activity against viruses than the p42 isoform ${ }^{37}$. p46 is also known to be the only OAS1 isoform which is robustly upregulated during infection ${ }^{29}$. Although further studies are needed to fully elucidate the functional relevance of the $\mathrm{PQTL}$ and $\mathrm{SQTL}$ for OAS1, the antiviral activity of the gene products is higher for the Neandertal haplotype than the common haplotype in Europeans ${ }^{30}$. In Europeans the Neandertal haplotype has undergone positive selection ${ }^{29}$ and the rs4767027-T allele reaches an allele frequency of 0.32 , whereas it is absent in sub-Saharan African populations. The association between the Neanderthal haplotype and protection against severe COVID-19 was recently described ${ }^{38}$. Using MR and measurements of circulating proteins, we demonstrated here that increased OAS1 levels of the Neandertal haplotype confers this protective effect.

Our MR evidence indicated that higher p46 isoform levels of OAS1 and higher OAS1 total protein levels, as measured by the SomaScan ${ }^{\circledR}$ assay had protective effects on COVID-19 outcomes. These results were strongly supported by colocalization analysis. Given the consistent colocalization between the sQTL and $\mathrm{pQTL}$ for OAS1, the lack of colocalization between the eQTL and pQTL for OAS1, and the evidence that the SomaScan ${ }^{\circledR}$ assay likely measures p46 isoforms, rather than total protein levels, it seems probable that the protective effect of OAS1 is derived from the p46 isoform. However, further investigations are required to specifically measure each isoform in circulation.

In light of the protective effect of the ancestral OAS1 splice variant (rs10774671-G) on COVID-19 and the positive selection of the Neandertal haplotype in Europeans, the loss-of-function variant (rs10774671-A) found in non-African population is surprising. Several scenarios might explain this loss-of-function, e.g., loss of purifying selection during the out-Africa exodus due to changes in environmental pathogens. Moreover, immune responses can be harmful and loss-of-function in OAS1-antiviral activity has been observed in several primates ${ }^{39}$, suggesting a cost of OAS1 activity. Nevertheless, our results indicate that interbreeding between Neanderthals and modern humans confers some protection against COVID-19. 
medRxiv preprint doi: https://doi.org/10.1101/2020.10.13.20212092; this version posted December 24, 2020. The copyright holder for this preprint (which was not certified by peer review) is the author/funder, who has granted medRxiv a license to display the preprint in perpetuity.

It is made available under a CC-BY-NC-ND 4.0 International license .

384 The OAS1 Neanderthal variant is another risk-modulating locus reported to be inherited from

385 Neanderthals, the other being the chromosome 3 risk locus ${ }^{40}$.

OAS1, OAS2 and OAS3 share significant homology and differ only in their number of OAS units. They also increase expression of both IRF3 and IRF7, both genes involved in interferon-induced gene expression. As an interferon stimulated gene ${ }^{41}, O A S 1$ polymorphisms have been associated with the host immune response to several classes of viral infection including influenza ${ }^{42}$, herpes simplex ${ }^{43}$, hepatitis $\mathrm{C}$,

391 West Nile ${ }^{44}$ Dengue ${ }^{45}$, and SARS-CoVV ${ }^{46}$ viruses. Given that OAS1 is an intracellular enzyme leading to 392 viral RNA degradation, it is probable that the circulating levels of this enzyme reflect intracellular levels of 393 this protein. However, there exists considerable evidence that circulating OAS1 is also important in the 394 viral immune response ${ }^{47}$.

Molecules currently exist which can increase OAS1 activity. Interferon beta-1b, which activates a cytokine cascade leading to increased OAS1 expression, ${ }^{48}$ is currently used to treat multiple sclerosis and has been shown to induce OAS1 expression in blood. ${ }^{49}$ Interferon-based therapy has also been used in other viral infections ${ }^{50}$. However, recent randomized trials have shown inconsistent results. While intravenous interferon beta-1b combined with lopinavir-ritonavir reduced mortality due to MERS-CoV infections, ${ }^{51}$ in 401 the unblinded SOLIDARITY trial, ${ }^{52}$ there was no demonstrated benefit of intravenous interferon-beta- $1 \mathrm{~b}$.

402 On the other hand, a recent phase II trial testing the effect of inhaled nebulized interferon beta-1b showed 403 improved symptoms in the treatment arm..$^{53}$ While this study was not powered to show a difference in 404 mortality, all deaths occurred in the placebo group. Inhaled nebulized interferon-1-beta results in a much 405 higher tissue availability in the lung and may result in improved anti-viral activity. Moreover, timing of 406 administration is likely to play a role, as the administration of a pro-inflammatory cytokine may not provide 407 benefit during the inflammation driven phase of the disease. However, data on timing of administration is 408 currently unavailable in the SOLIDARITY trial, and conclusions cannot yet be drawn. Lastly the effect of 409 interferon supplement may vary across ancestral population, as different ancestries have different 410 amounts of the more active p46 isoform of OAS1. Our study was limited to individuals of European 
medRxiv preprint doi: https://doi.org/10.1101/2020.10.13.20212092; this version posted December $24,2020$. The copyright holder for this preprint (which was not certified by peer review) is the author/funder, who has granted medRxiv a license to display the preprint in perpetuity.

It is made available under a CC-BY-NC-ND 4.0 International license .

411 ancestry, a population with higher expression of the p46 isoform. Interestingly, the SOLIDARITY trial

412 enrolled $61 \%$ of its patients in Africa or Asia, and $17 \%$ in Latin America, populations with higher

413 expression of the p42 isoform OAS1, while the study on inhaled interferon beta- $1 \mathrm{~b}$ was comprised of $80 \%$

414 White patients from the United Kingdom. This suggests that interferon beta-1b may have different effects

415 in populations of different ancestry, due to presence of different genetic variants.

417 In-vitro evidence also exists demonstrating that pharmacological inhibition of phosphodiesterase-12,

418 which normally degrades the OAS enzymes, potentiates this OAS-mediated antiviral activity. ${ }^{54}$ PDE-12

419 inhibitors potentiate the action of OAS1, 2 and 3. ${ }^{55}$ Interestingly other coronaviruses in the same

420 betacoronavirus family as SARS-CoV-2 have been shown to produce viral proteins that degrade the OAS

421 family of proteins, and antagonize RNase-L activity, leading to evasion of the host immune response. ${ }^{56,57}$

422 Thus classes of medications currently exist that lead to increased OAS1 levels and could be explored for

423 their effect upon COVID-19 outcomes.

425 Our MR analyses found that higher level of OAS3 expression is associated with worse COVID-19

426 outcomes, which is an opposite direction of effect compared to OAS1. The discordant effects of the

427 Neanderthal haplotype for OAS1 and OAS3 were also reported by a previous study ${ }^{29}$, which might reflect

428 complex biology of OAS genes for innate immune response. In a recent transcription-wide association

429 study from the GenOMICC program ${ }^{22}$, genetically-predicted high expression of OAS3 in lungs and whole

430 blood were associated with higher risk of becoming critically ill COVID-19 patients. Although further

431 studies to assess the roles of OAS genes specific to SARS-CoV-2 are needed, it is likely that OAS1 is the

432 main driver of the protective effect of Neanderthal haplotype for COVID-19 outcomes given prior

433 functional studies demonstrating the antiviral effect of OAS genes ${ }^{29}$.

IL10RB encodes for the beta subunit of the IL10 receptor (a type III interferon receptor), and is part of a cluster of immunologically important genes including IFNAR1 and IFNAR2, both recently implicated in 
medRxiv preprint doi: https://doi.org/10.1101/2020.10.13.20212092; this version posted December 24, 2020. The copyright holder for this preprint (which was not certified by peer review) is the author/funder, who has granted medRxiv a license to display the preprint in perpetuity.

It is made available under a CC-BY-NC-ND 4.0 International license .

437

438

439

440

441

442

443

444

445

446

447

448

449

450

451

452

453

454

455

456

457

severe COVID-19 pathophysiology.58 IFNAR1 and 2 encode the interferon alpha/beta receptor subunits 1 and 2, respectively. Interestingly, while there exists a cis-pQTL strongly associated with IFNAR1 levels, it was not associated with any of the COVID-19 outcomes (P 0.5). Further, IFNAR1 had no trans-pQTLs identified, which means that the IL10RB cis-pQTL does not likely reflect IFNAR1 levels. However, since IFNAR2 was not measured in any proteomic studies, we could not test the effect of its circulating levels on COVID-19 outcomes. IL10RB mediates IL10 anti-inflammatory activity through its downstream inhibitory effect on many well-known pro-inflammatory cytokines such as janus kinases and STAT1.59 While overexpression of IL10 has been involved in the persistence of multiple chronic bacterial infections such as tuberculosis, ${ }^{60}$ its role remains poorly understood in acute infections. In sepsis, a disease state characterized by high levels of cytokine activity and a rise in multiple biomarkers associated with inflammation, there is also a well-established increase in anti-inflammatory IL10 production by leukocytes, especially in the early stage of the disease.$^{61}$ Most importantly, while in a normal physiological state, IL10 is usually only produced at a low level by neutrophils, monocytes and macrophages, its production is strongly upregulated by IL4, itself upregulated by lipopolysaccharides (LPS) when they bind LBPs. ${ }^{62,63}$ Interestingly, while the LBP gene did not pass FDR correction, it was still one of the most significant protein in our MR cis-pQTL analysis (Table S1, S3). While LPS's are well-known for their role in triggering gram-negative bacterial sepsis, their role in other acute infections and respiratory diseases is likely broader, and involves complex sequences of cytokine signaling ${ }^{64-67}$ Nevertheless, as our MR studies showed that IL10RB protein level affected COVID-19 outcome with a concordant effect direction, and given the known role of overt inflammation in COVID-19 morbidity, this pathway likely deserves more investigation.

This study has limitations. First, we used MR to test the effect of circulating protein levels measured in a non-infected state. This is because the effect of the cis-pQTLs upon circulating proteins was estimated in individuals who had not been exposed to SARS-CoV-2. Once a person contracts SARS-CoV-2 infection, levels of circulating proteins could be altered and this may be especially relevant for cytokines such as IL10 (which binds to IL10RB), whose levels may reflect host response to the viral infection and OAS1, 
medRxiv preprint doi: https://doi.org/10.1101/2020.10.13.20212092; this version posted December 24, 2020. The copyright holder for this preprint (which was not certified by peer review) is the author/funder, who has granted medRxiv a license to display the preprint in perpetuity.

It is made available under a CC-BY-NC-ND 4.0 International license .

464 whose levels are increased by activation of interferon pathway, as we observed in our case-control study

465 (Figures S4, S6, S9). Thus, the MR results presented in this paper should be interpreted as an

466 estimation of the effect of circulating protein levels, when measured in the non-infected state. On-going

467 studies will help to clarify if the same cis-pQTLs influence circulating protein levels during infection.

468 Second, this type of study suffers a high false-negative rate. Our goal was not to identify every circulating

469 protein influencing COVID-19 outcomes, but rather to provide evidence for few proteins with strong cis-

470 PQTLs since these proteins are more likely to be robust to the assumptions of MR studies. Future large-

471 scale proteomic studies with more circulating proteins properly assayed should help to overcome these

472 limitations. Third, most MR studies assume a linear relationship between the exposure and the outcome.

473 Thus, our findings would not identify proteins whose effect upon COVID-19 outcomes has a clear

474 threshold effect. Finally, we could not completely exclude the possibility that measurement of OAS1 levels

475 may be influenced by protein altering variants, however, such variants do not affect sQTL RNA-

476 sequencing studies and the association between OAS1 levels and COVID-19 outcomes remained robust

477 in such analyses.

479 In conclusion, we have used genetic determinants of circulating protein levels and COVID-19 outcomes

480 obtained from large-scale studies and found compelling evidence that OAS1 has a protective effect on

481 COVID-19 susceptibility and severity. Measuring OAS1 levels in a case-control study demonstrated that

482 higher OAS1 levels in a non-infectious state were associated with reduced risk of COVID-19 outcomes.

483 Interestingly, the available evidence suggests that the protective effect from OAS1 is likely due to the

484 Neanderthal introgressed p46 OAS1 isoform. Known pharmacological agents that increase OAS1 levels

485 could be explored for their effect on COVID-19 outcomes. 
medRxiv preprint doi: https://doi.org/10.1101/2020.10.13.20212092; this version posted December $24,2020$. The copyright holder for this preprint (which was not certified by peer review) is the author/funder, who has granted medRxiv a license to display the preprint in perpetuity.

It is made available under a CC-BY-NC-ND 4.0 International license .

488

489

490

491

492

493

494

495

496

497

498

499

500

501

502

503

504

505

506

507

508

509

510

511 Hospitalized COVID-19 cases were defined as individuals hospitalized with laboratory confirmed SARS512 CoV-2 infection (using the same microbiology methods as for the very severe phenotype), where

pQTL GWAS

We systematically identified pQTL associations from six large proteomic GWASs. ${ }^{15-20}$ Each of these studies undertook proteomic profiling using either SomaLogic ${ }^{\circledR}$ technology, or O-link proximal extension assays.

\section{COVID GWAS and COVID-19 Outcomes}

To assess the association of cis-pQTLs with COVID-19 outcomes, we used the largest COVID-19 metaanalytic GWAS to date from the COVID-19 Host Genetics Initiative ${ }^{21}$. For our study, we used three of these GWAS meta-analyses which included 25 cohorts of European ancestry and 1 cohort of admixed American ancestry, based on sample size and clinical relevance. These outcomes were very severe COVID-19, hospitalization due to COVID-19, and susceptibility to COVID-19 (named A2, B2, and C2, respectively in the COVID-19 Host Genetics Initiative).

Very severe COVID-19 cases were defined as hospitalized individuals with COVID-19 as the primary reason for hospital admission with laboratory confirmed SARS-CoV-2 infection (nucleic acid amplification tests or serology based), and death or respiratory support (invasive ventilation, continuous positive airway pressure, Bilevel Positive Airway Pressure, or continuous external negative pressure, high-flow nasal or face-mask oxygen). Simple supplementary oxygen (e.g. 2 liters/minute via nasal cannula) did not qualify for case status. Controls were all individuals in the participating cohorts who did not meet this case definition. 
medRxiv preprint doi: https://doi.org/10.1101/2020.10.13.20212092; this version posted December 24, 2020. The copyright holder for this preprint (which was not certified by peer review) is the author/funder, who has granted medRxiv a license to display the preprint in perpetuity.

It is made available under a CC-BY-NC-ND 4.0 International license .

513 hospitalization was due to COVID-19 related symptoms. Controls were all individuals in the participating 514 cohorts who did not meet this case definition.

516 Susceptibility to COVID-19 cases were defined as individuals with laboratory confirmed SARS-CoV-2

517 infection, health record evidence of COVID-10 (international classification of disease coding or physician

518 confirmation), or with self-reported infections (e.g. by questionnaire). Controls were all individuals in the 519 participating cohorts who did not meet this case definition.

\section{Two-sample Mendelian randomization}

522 We used two-sample MR analyses to screen and test potential circulating proteins for their role

523 influencing COVID-19 outcomes. In two-sample MR, the effect of SNPs on the exposure and outcome are

524 taken from separate GWASs. This method often improves statistical power, because it allows for larger 525 sample sizes for the exposure and outcome GWAS. ${ }^{68}$

527 Exposure definitions: We conducted MR using six large proteomic GWAS studies. ${ }^{15-20}$ Circulating

528 proteins from Sun et al, Emilsson et al and Pietzner et al were measured on the Somalogic platform,

529 Suhre et al, Yao et al and Folkersen et al used protein measurements on the O-link platform. We selected

530 proteins with only cis-pQTLs to test their effects on COVID-19 outcomes, because they are less likely to

531 be affected by potential horizontal pleiotropy. The cis-pQTLs were defined as the genome-wide significant

532 SNPs $\left(P<5 \times 10^{-8}\right)$ with the lowest $P$ value within $1 \mathrm{Mb}$ of the transcription start site (TSS) of the gene 533 encoding the measured protein. ${ }^{9}$ For proteins from Emilsson et al, Pietzner et al, Suhre et al, Yao et al 534 and Folkersen et al, we used the sentinel cis-pQTL per protein per study as this was the data available.

535 For proteins from Sun et al, we used PLINK and 1000 genome European population references (1KG 536 EUR) to clump and select LD-independent cis-pQTL (R2<0.001, distance $1000 \mathrm{~kb})$ with the lowest $\mathrm{P}$ -

537 value from reported summary statistics for each SOMAmer ${ }^{\circledR}$ bound proteins. We included the same 538 proteins represented by different cis-pQTLs from different studies in order to cross examine the findings. 
medRxiv preprint doi: https://doi.org/10.1101/2020.10.13.20212092; this version posted December 24, 2020. The copyright holder for this preprint (which was not certified by peer review) is the author/funder, who has granted medRxiv a license to display the preprint in perpetuity.

It is made available under a CC-BY-NC-ND 4.0 International license .

539

540

541

542

543

544

545

546

547

548

549

550

551

552

553

554

555

For cis-pQTLs that were not present in the COVID-19 GWAS, SNPs with LD $\mathrm{R}^{2}>0.8$ and with minor allele frequency $(\mathrm{MAF})<0.42$ were selected as proxies, MAF $>0.3$ was used for allelic alignment for proxy SNPs. cis-pQTLs with palindromic effects and with minor allele frequency (MAF) $>0.42$ were removed prior to MR to prevent allele-mismatches. Benjamini \& Hochberg correction was used to control for the total number of proteins tested using MR. We recognize that this is an overly conservative correction, given the non-independence of the circulating proteins, but such stringency should reduce false positive associations. MR analyses were performed using the TwoSampleMR package in R. ${ }^{69}$ For proteins with a single (sentinel) cis-pQTL, we used the Wald ratio to estimate the effect of each circulating protein on each of the three COVID-19 outcomes. For any proteins/SOMAmer ${ }^{\circledR}$ reagents with multiple independent cis-pQTL, an inverse variance weighted (IVW) method was used to meta-analyze their combined effects. After harmonizing the cis-pQTLs of proteins with COVID-19 GWAS, a total of 566 SOMAmer ${ }^{\circledR}$ reagents (529 proteins, 565 directly matched IVs and 26 proxies) from Sun et al, 760 proteins (747 directly matched IVs and 11 proxies) from Emilsson et al, 91 proteins (90 directly matched IVs and 2 proxies) from Pietzner et al, 74 proteins (72 directly matched IVs) from Suhre et al, 24 proteins (24 directly matched IVs) from Yao et al and 13 proteins (13 directly matched IVs) from Folkersen et al were used as instruments for the MR analyses across the three COVID-19 outcomes (Table S11-12). ${ }^{15-20}$

\section{Pleiotropy assessments}

A common pitfall of MR is horizontal pleiotropy, which occurs when the genetic variant affects the outcome via pathways independent of circulating proteins. The use of circulating protein cis-pQTLs greatly reduces the possibility of pleiotropy, for reasons described above. We also searched in the PhenoScanner database, a large catalogue of observed SNP-outcome relationships involving $>5,000$ GWAS done to date to assess potentially pleiotropic effects of the cis-pQTLs of MR prioritized proteins, by testing the association of cis-pQTLs with other circulating proteins (i.e. if they were trans-pQTLs to other proteins or traits). For cis-pQTLs of MR prioritized proteins, if they were measured on SomaLogic ${ }^{\circledR}$ platform, we assessed the possibility of potential aptamer-binding effects (where the presence of protein altering variants may affect protein measurements). We also checked if cis-pQTLs of MR prioritized 
medRxiv preprint doi: https://doi.org/10.1101/2020.10.13.20212092; this version posted December 24, 2020. The copyright holder for this preprint (which was not certified by peer review) is the author/funder, who has granted medRxiv a license to display the preprint in perpetuity.

It is made available under a CC-BY-NC-ND 4.0 International license .

566 proteins had significantly heterogeneous associations across COVID-19 populations in each COVID-19 567 outcome GWAS.

570 Finally, we tested colocalization of the genetic signal for the circulating protein and each of the three

571 COVID-19 outcomes using colocalization analyses, which assess potential confounding by LD.

572 Specifically, for each of these MR significant proteins with genome-wide summary data available, for the 573 proteomic GWASs, a stringent Bayesian analysis was implemented in coloc $\mathrm{R}$ package to analyze all

574 variants in $1 \mathrm{MB}$ genomic locus centered on the cis-pQTL. Colocalizations with posterior probability for

575 hypothesis 4 (PP4, that there is an association for both protein level and COVID-19 outcomes and they

576 are driven by the same causal variant) $>0.5$ were considered likely to colocalize (which means the 577 highest posterior probability for all 5 coloc hypotheses), and PP4 > 0.8 was considered to be highly likely 578 to colocalize.

sQTL and eQTL MR and colocalization studies for OAS genes

581 We performed MR and colocalization analysis using GTEx project v8 ${ }^{33}$ GWAS summary data to 582 understand the effects of expression and alternative splicing of OAS genes in whole blood. The genetic 583 instruments were conditionally independent $\left(\mathrm{R}^{2}<0.001\right) \mathrm{sQTL}$ and eQTL SNPs for OAS1, eQTL for 584 OAS2 and OAS3 identified by using stepwise regression in GTEx ${ }^{33}$. The sQTL SNP for OAS1 585 (rs10774671), was originally identified for the normalized read counts of LeafCutter ${ }^{31}$ cluster of the last 586 intron of p46 isoform (chr12:112,917,700-112,919,389 GRCh38) in GTEx ${ }^{32}$, and was used to estimate the 587 effect of p46 isoform. Colocalization analysis was performed using GWAS summary from GTEx by 588 restricting the regions within $1 \mathrm{Mb}$ of rs4767027. 
medRxiv preprint doi: https://doi.org/10.1101/2020.10.13.20212092; this version posted December 24, 2020. The copyright holder for this preprint (which was not certified by peer review) is the author/funder, who has granted medRxiv a license to display the preprint in perpetuity.

It is made available under a CC-BY-NC-ND 4.0 International license .

591 BQC19 is a Québec-wide initiative to enable research into the causes and consequences of COVID-19

592 disease. For this analysis, we used results from patients with available proteomic data from SomaLogic ${ }^{\circledR}$

593 assay (Supplementary Data). The patients were recruited at the Jewish General Hospital (JGH) and

594 Centre hospitalier de l'Université de Montréal (CHUM) in Montréal, Québec, Canada.

COVID-19 case - control status was defined to be consistent with the GWAS study from COVID-19 HGI, from which the MR results were derived. Namely, we tested the association of OAS1 protein levels with the three different COVID-19 outcome definitions both in samples procured from non-infected samples and from samples during the acute phase of the infection. The three outcomes were: 1) Very severe COVID-19-defined as hospitalized individuals with laboratory confirmed SARS-CoV-2 infection (nucleic

601 acid amplification tests or serology based), and death or respiratory support (invasive ventilation, 602 continuous positive airway pressure, Bilevel Positive Airway Pressure, or continuous external negative 603 pressure, high flow nasal or face-mask oxygen). Controls were all individuals who did not meet this case 604 definition; 2) Hospitalized COVID-19 cases—defined as individuals hospitalized with laboratory confirmed 605 SARS-CoV-2 infection. Controls were all who did not meet this case definition; 3) Susceptibility to COVID19-cases were defined as individuals with laboratory confirmed SARS-CoV-2 infection, and controls

607 were all individuals who underwent PCR testing for SARS-CoV-2, but were negative. The date of 608 symptom onset for COVID-19 patients was collected from patients' charts or estimated from their first 609 positive COVID-19 tests if missing. Case inclusion criteria was not exclusive, which means that some 610 individuals who were cases in the susceptibility analyses were also included in the hospitalization and 611 very severe COVID-19 if they met case definitions.

614 infectious state as those sampled within 14 days (including the $14^{\text {th }}$ day) from the first date of symptoms ${ }^{70}$.

615 For individuals with more than one sample within 14 days of symptom onset, the earliest sample was 616 used. We defined samples procured from patients who were non-infectious as samples from SARS-CoV6172 positive patients taken at least 31 days after symptom onset or from SARS-CoV-2 negative individuals. 
medRxiv preprint doi: https://doi.org/10.1101/2020.10.13.20212092; this version posted December 24, 2020. The copyright holder for this preprint (which was not certified by peer review) is the author/funder, who has granted medRxiv a license to display the preprint in perpetuity.

It is made available under a CC-BY-NC-ND 4.0 International license .

618 We selected 31 days, as this is the upper limit of the intra-quartile range of the duration of SARS-CoV-2 619 positivity in a recent systematic review and coincided with the first scheduled outpatient follow-up blood

620 test in the BQC1971. For individuals with more than one sample at least 31 days of symptom onset, the

621 latest sample was used. Protein levels in citrated (ACD) plasma samples were measured using the

622 SomaScan® assay [SomaLogic Inc.]. Details regarding SOMAmer QC are included in Supplementary

623 Data.

624

6251039 samples from 399 SARS-CoV-2 positive patients and 105 SARS-CoV-2 negative patients of mainly

626 European descent underwent SomaScan ${ }^{\circledR}$ assays, which included 5,284 SOMAmer reagents, targeting

6274,742 proteins. A total of 125 individuals were recruited from CHUM and 279 individuals were recruited

628 from the JGH. Individuals had blood sampling done at up to five different time points (200 individuals had

629 one measurement, 113 individuals had two measurements, 152 individuals had three measurements, 38

630 individuals had four measurements and 1 individual had five measurements). Days from symptom onset

631 were calculated for each sample based on the date of symptom and blood draw date. Sample processing

632 time (in hours) for each sample was also calculated measure the duration of time from sample collection

633 to processing to account for the changes in the amount of protein released from cell lysis due to sample

634 handling time.

635

636 Sample QC was performed to remove outliers with long sample processing time and high OAS1 levels.

637 OAS1 level was measured by one SOMAmer reagent (OAS1.10361.25). Within each group, normalized

638 OAS1 levels were natural log transformed, adjusted for sample processing time and the residuals were

639 further standardized. Logistic regression was performed to test the association standardized OAS1 level

640 with the three COVID-19 outcomes including age, sex, $\mathrm{age}^{2}$, center of recruitment and plates as

641 covariates.

642

643 
medRxiv preprint doi: https://doi.org/10.1101/2020.10.13.20212092; this version posted December $24,2020$. The copyright holder for this preprint (which was not certified by peer review) is the author/funder, who has granted medRxiv a license to display the preprint in perpetuity.

It is made available under a CC-BY-NC-ND 4.0 International license .

644

645

646

647

648

649

650

651

652

653

654

655

656

657

658

659

660

661

662

663

664

665

666

667

\section{Acknowledgements:}

We thank Dr. Luis Barriero for his comments on the introgressed Neanderthal p46 isoform, and Dr. Nicolas Chomont for the discussion on the clinical phenotype of BQC19. We would like to also thank the MI4 and the MUHC Foundation that contributed for the SomaLogic ${ }^{\circledR}$ panel.

\section{Ethics declarations:}

All cohorts contributing cohorts to COVID-19 HGI received ethics approval from their respective research ethics review boards. The Biobanque Quebecoise de la COVID-19 (BQC19) received ethical approval from the IRB of JGH and the CHUM.

\section{Data availability:}

Data from proteomics studies and GTEx consortium are available from the referenced peer-reviewed studies or their corresponding authors, as applicable. Summary statistics for the COVID-19 outcomes are publicly available for download on the COVID-19 HGI website (www.covid19hg.org). Applicants are invited to apply for access to BQC19 data from the JGH hospital (https://www.mcgill.ca/genepi/mcg-covid19-biobank) and/or the BQC19 (bqc19.ca).

\section{Author contributions:}

Conception and design: SZ, GBL and JBR. Data analyses: SZ and TN. Data acquisition: TN, GBL, DM, DEK, JA, MA, LL, EBR, DH, NK, ZA, NR, MB, LP, CG, XX, CT, BV, OA, TA, NA, MC, MD, VF, DEK and JBR. Interpretation of data: SZ, GBL, TN, MP, YC, DEK, VF and JBR. Funding acquisition: DM, VM, VF, JBR. Methodology: SZ, KZ, CMTG and JBR. Project administration: DM, VF and JBR. Validation: SZ, TN, MP, NK, MP, JN, ET, CL, DEK and JBR. Visualization: SZ, TN and VF. Writing-original draft: SZ, GBL, TN and JBR. Writing-review \& editing: SZ, GBL, TN, MP, HZ, VM, MP, RF, ML, MH, CP, DEK and JBR. All authors were involved in preparation of the further draft of the manuscript and revising it critically for content. All authors gave final approval of the version to be published. The corresponding author attests that all listed authors meet authorship criteria and that no others meeting the criteria have been omitted. 
Table 1. MR-Identified Circulating Protein Levels Effecting COVID-19 Outcomes

\begin{tabular}{|c|c|c|c|c|c|c|c|c|c|c|c|c|c|c|}
\hline \multirow[t]{2}{*}{ Protein } & \multirow[t]{2}{*}{ cis-pQTL } & \multirow[t]{2}{*}{ Source } & \multicolumn{4}{|c|}{$\begin{array}{c}\text { Very Severe COVID-19 } \\
\text { (99.7\% European Ancestry) }\end{array}$} & \multicolumn{4}{|c|}{$\begin{array}{c}\text { Hospitalization } \\
\text { (European Ancestry Only) }\end{array}$} & \multicolumn{4}{|c|}{$\begin{array}{c}\text { Susceptibility } \\
\text { (European Ancestry Only) }\end{array}$} \\
\hline & & & OR & $95 \% \mathrm{Cl}$ & $P$ value & $P$ het & OR & $95 \% \mathrm{Cl}$ & $P$ value & $P$ het & OR & $95 \% \mathrm{Cl}$ & $P$ value & $P$ het \\
\hline OAS1 & rs4767027 & Sun & 0.54 & $\begin{array}{l}0.44- \\
0.68\end{array}$ & $7.0 \times 10^{-8}$ & 0.37 & 0.61 & $0.51-0.73$ & $8.3 \times 10^{-8}$ & 0.16 & 0.78 & $0.69-0.87$ & $7.6 \times 10^{-6}$ & 0.005 \\
\hline $\mathrm{ABO}$ & rs505922 & $\begin{array}{l}\text { Sun, } \\
\text { Emilsson }\end{array}$ & 1.09 & $\begin{array}{l}1.05- \\
1.14\end{array}$ & $6.4 \times 10^{-5}$ & 0.10 & 1.11 & $1.07-1.15$ & $6.8 \times 10^{-9}$ & 0.06 & 1.07 & $1.05-1.10$ & $1.1 \times 10^{-9}$ & 0.10 \\
\hline IL10RB & rs2834167 & Emilsson & 0.47 & $\begin{array}{l}0.32- \\
0.68\end{array}$ & $7.1 \times 10^{-5}$ & 0.02 & 0.53 & $0.39-0.73$ & $8.8 \times 10^{-5}$ & 0.11 & 0.87 & $0.72-1.07$ & 0.18 & 0.006 \\
\hline
\end{tabular}

OR: represents the estimated effect of a standard deviation on the natural log scale (for Sun et al) or one unit (for Emilsson et al) increase in protein levels on the odds of the three COVID-19 outcomes. $P$ het: $P$ value of heterogeneity for each cis-pQTLs across the cohorts in the GWAS summary-level meta-analysis from COVID-19 Host Genomic Initiative. 
medRxiv preprint doi: https://doi.org/10.1101/2020.10.13.20212092; this version posted December 24, 2020. The copyright holder for this preprint (which was not certified by peer review) is the author/funder, who has granted medRxiv a license to display the preprint in perpetuity.

It is made available under a CC-BY-NC-ND 4.0 International license .

Table 2. Participant demographics for the BQC19 cohort

\begin{tabular}{|c|c|}
\hline Sample Demographics & $\begin{array}{c}\text { Total } \\
(\mathrm{N}=504)\end{array}$ \\
\hline \multicolumn{2}{|l|}{ Sex } \\
\hline Female & $250(49.6 \%)$ \\
\hline Male & $254(50.4 \%)$ \\
\hline Age (years) * & $65.4(18.0)$ \\
\hline BMI* $^{*}$ & $28.6(6.18)$ \\
\hline Missing & $225(44.6 \%)$ \\
\hline \multicolumn{2}{|l|}{ SARS-CoV-2 PCR test } \\
\hline Positive & $399(79.2 \%)$ \\
\hline Negative & $105(20.8 \%)$ \\
\hline \multicolumn{2}{|l|}{ Hospitalization } \\
\hline Hospitalized & $406(80.6 \%)$ \\
\hline Outpatient treatment only & $98(19.4 \%)$ \\
\hline Hospitalization duration (days) $^{\dagger}$ & $14.0[6.00,27.0]$ \\
\hline \multicolumn{2}{|l|}{ Death } \\
\hline Deceased & $43(8.5 \%)$ \\
\hline Survived & $461(91.5 \%)$ \\
\hline \multicolumn{2}{|l|}{ Respiratory Support } \\
\hline No oxygen & $233(46.2 \%)$ \\
\hline Oxygen supplement & $143(28.4 \%)$ \\
\hline Mechanical Ventilation & $128(25.4 \%)$ \\
\hline Days on ventilator $^{\dagger}$ & $14.0[6.75,23.5]$ \\
\hline
\end{tabular}

* Mean (SD) and † Median (25\%QR, 75\%QR), which was calculated amongst those who were hospitalized and those on ventilator, respectively. 
medRxiv preprint doi: https://doi.org/10.1101/2020.10.13.20212092; this version posted December 24, 2020. The copyright holder for this preprint (which was not certified by peer review) is the author/funder, who has granted medRxiv a license to display the preprint in perpetuity.

It is made available under a CC-BY-NC-ND 4.0 International license .

\section{Figure 1. Flow Diagram of Study Design}

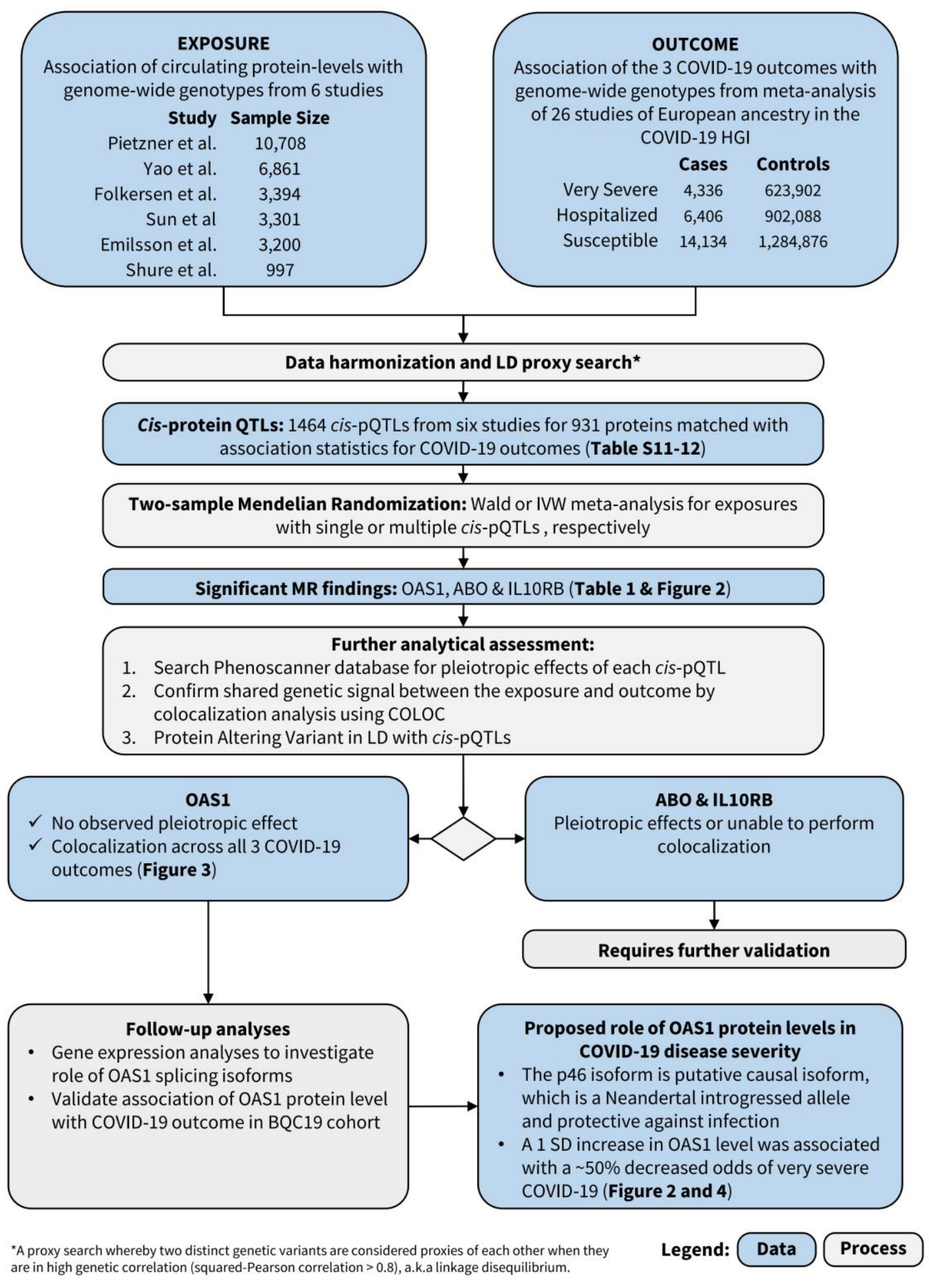


Figure 2. Association of Circulating Protein Levels of OAS1, ABO and IL10RB and mRNA levels of OAS1 with COVID-19 Outcomes from MR

A

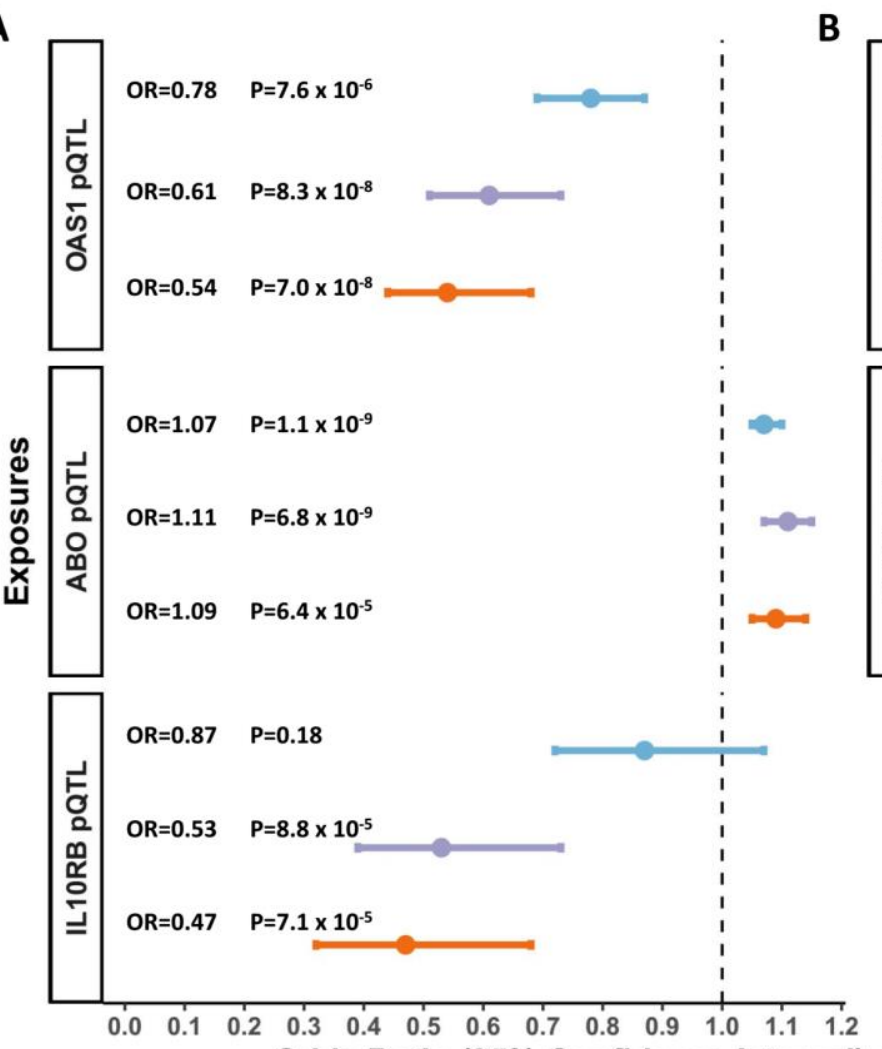

B

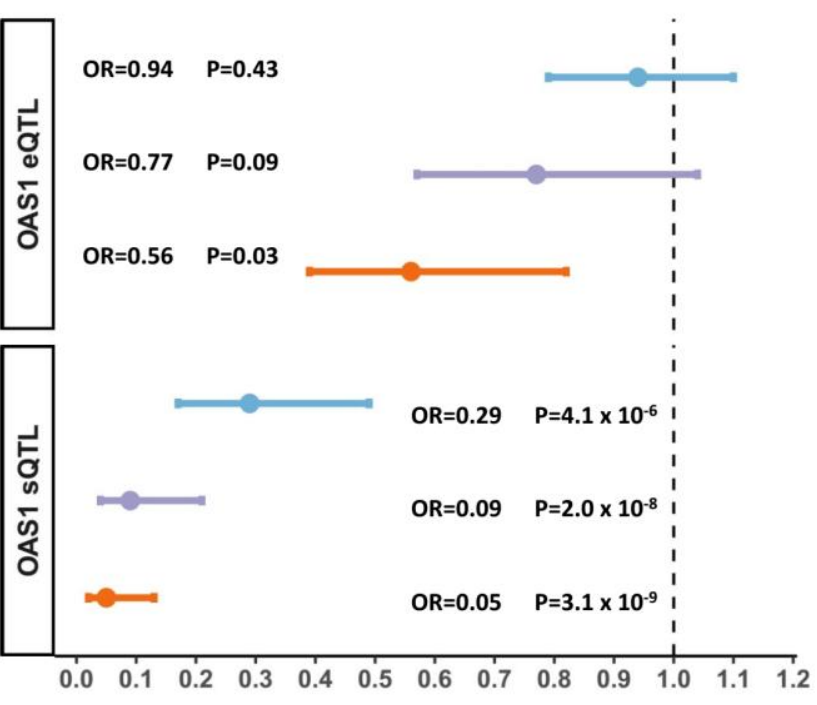

COVID-19 Outcomes

- Susceptibility

+ Hospitalization

+ Very Severe

Odds Ratio (95\% Confidence Interval) per unit* increase of log exposure level

A: MR estimates of proteins influencing COVID-19 outcomes, unit: standard deviation of log normalized value;

B. MR estimates of OAS1 mRNA influencing COVID-19 outcomes, unit: standard deviation of normalized read counts. 
medRxiv preprint doi: https://doi.org/10.1101/2020.10.13.20212092; this version posted December 24, 2020. The copyright holder for this preprint (which was not certified by peer review) is the author/funder, who has granted medRxiv a license to display the preprint in perpetuity.

It is made available under a CC-BY-NC-ND 4.0 International license .

Figure 3. Colocalization of the Genetic Determinants of OAS1 Plasma Protein Levels and COVID-19 Outcomes
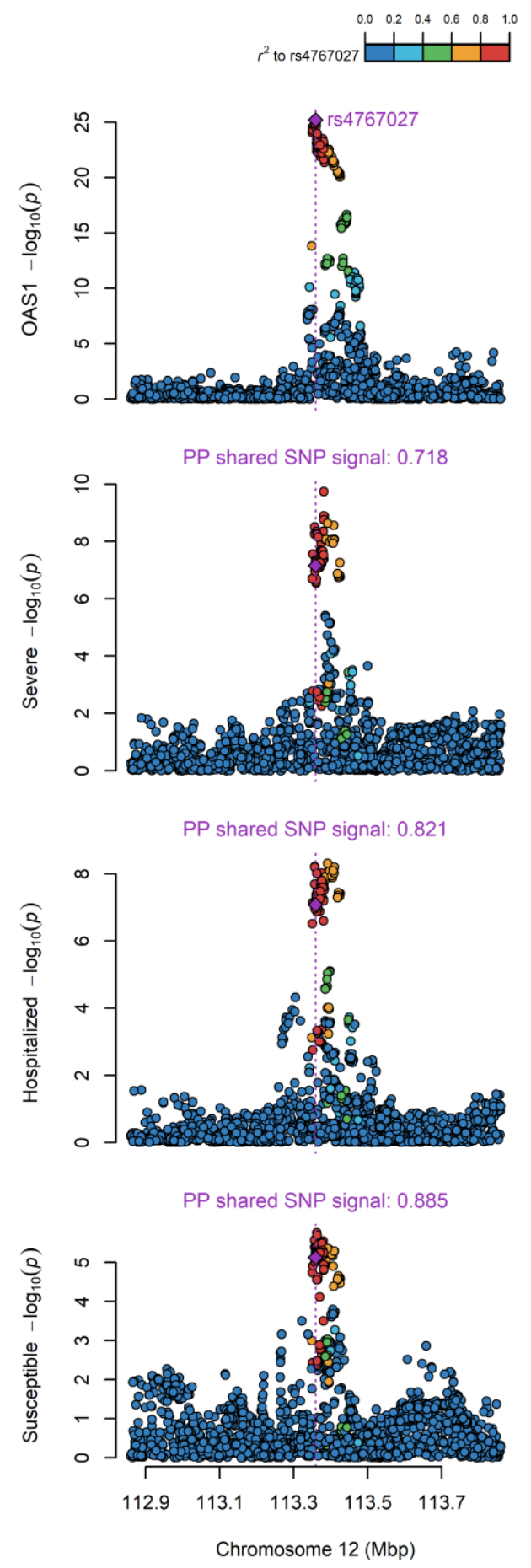

Colocalizatinon of genetic signal of $1 \mathrm{MB}$ region around OAS1 pQTL rs4767027 of OAS1 level (top plot) and COVID-19 outcomes (three bottom plot), color shows SNPs in the region in LD $\left(\mathrm{r}^{2}\right)$ to rs 4767027 (purple). Posterial probability (PP) of shared signal between OAS1 level and three COVID-19 ouctomes are estimated by coloc. 
Figure 4. Association of OAS1 levels with COVID-19 Outcomes from the Case-Control Study in BQC19

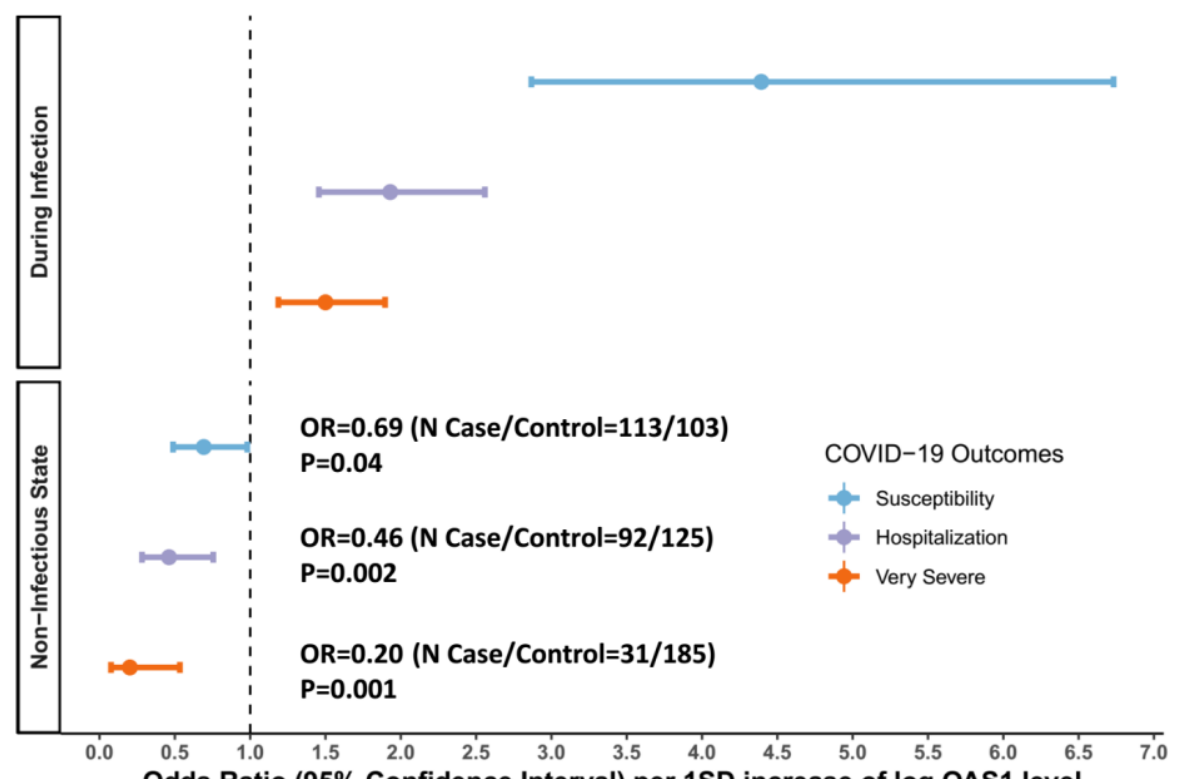

\section{$\mathrm{OR}=4.39$ (N Case/Control=308/103)} $P=1.1 \times 10^{-11}$

OR=1.92 ( $\mathrm{N}$ Case/Control=260/151) $\mathrm{P}=4.8 \times 10^{-6}$

$\mathrm{OR}=1.49$ ( $\mathrm{N}$ Case/Control $=90 / 321$ )

$\mathrm{P}=\mathbf{0 . 0 0 0 7}$

During Infection: Patient samples that were collected within 14 days from the date of symptom onset. For individuals with two or more samples collected within 14 days of symptom onset, the earliest time point was used.

Non-Infectious State: Patient samples that were collected at least 31 days from the date of symptom onset. For individuals with two or more samples collected at different time points at least 31 days from symptom onset, the latest time point was used.

Additional information is also described in table S10. 


\section{References}

1. Johns Hopkins. Corona Virus Resource Center. (2020).

2. David M. Weinreich, M.D., Sumathi Sivapalasingam, M.D., Thomas Norton, M.D., Shazia Ali, Pharm.D., Haitao Gao, Ph.D., Rafia Bhore, Ph.D., Bret J. Musser, Ph.D., Yuhwen Soo, Ph.D., Diana Rofail, Ph.D., Joseph Im, B.S., Christina Perry, M.B.A., Cynthia Pan, B. P. REGN-COV2, a Neutralizing Antibody Cocktail, in Outpatients with Covid-19. N. Engl. J. Med. (2020) doi:10.1056/NEJMoa2035002.

3. Dexamethasone in Hospitalized Patients with Covid-19 - Preliminary Report. N. Engl. J. Med. 1-11 (2020) doi:10.1056/nejmoa2021436.

4. Sterne, J. A. C. et al. Association between administration of systemic corticosteroids and mortality among critically ill patients with COVID-19: A meta-analysis. JAMA - J. Am. Med. Assoc. (2020) doi:10.1001/jama.2020.17023.

5. Beigel, J. H. et al. Remdesivir for the Treatment of Covid-19 - Preliminary Report. N. Engl. J. Med. 2019-2020 (2020) doi:10.1056/nejmoa2007764.

6. Cavalcanti, A. B. et al. Hydroxychloroquine with or without Azithromycin in Mild-toModerate Covid-19. N. Engl. J. Med. (2020) doi:10.1056/nejmoa2019014.

7. Nelson, M. R. et al. The support of human genetic evidence for approved drug indications. Nat. Genet. 47, 856-860 (2015).

8. Cook, D. et al. Lessons learned from the fate of AstraZeneca's drug pipeline: a fivedimensional framework. Nat. Rev. Drug Discov. 13, 419-31 (2014).

9. Zheng, J. et al. Phenome-wide Mendelian randomization mapping the influence of the plasma proteome on complex diseases. Nat. Genet. (2020) doi:10.1038/s41588-0200682-6.

10. Filbin, M. R. et al. Plasma proteomics reveals tissue-specific cell death and mediators of cell-cell interactions in severe COVID-19 patients. bioRxiv (2020).

11. Davey Smith, G., Ebrahim, S., Smith, G. D. \& Ebrahim, S. 'Mendelian randomization': Can genetic epidemiology contribute to understanding environmental determinants of disease? International Journal of Epidemiology vol. 32 1-22 (2003).

12. Giambartolomei, C. et al. Bayesian Test for Colocalisation between Pairs of Genetic Association Studies Using Summary Statistics. PLoS Genet. 10, (2014).

13. Lawlor, D. A., Tilling, K. \& Smith, G. D. Triangulation in aetiological epidemiology. Int. J. Epidemiol. (2016) doi:10.1093/ije/dyw314.

14. The COVID-19 Host Genetics Initiative, a global initiative to elucidate the role of host genetic factors in susceptibility and severity of the SARS-CoV-2 virus pandemic. Eur. J. Hum. Genet. 28, 715-718 (2020).

15. Sun, B. B. et al. Genomic atlas of the human plasma proteome. Nature 558, 73-79 (2018).

16. Emilsson, V. et al. Co-regulatory networks of human serum proteins link genetics to disease. Science (80-. ). 1327, 1-12 (2018). 
17. Pietzner, M. et al. Genetic architecture of host proteins interacting with SARS-CoV-2. bioRxiv Prepr. Serv. Biol. (2020) doi:10.1101/2020.07.01.182709.

18. Folkersen, L. et al. Mapping of 79 loci for 83 plasma protein biomarkers in cardiovascular disease. PLoS Genet. 13, e1006706 (2017).

19. Yao, C. et al. Genome-wide mapping of plasma protein QTLs identifies putatively causal genes and pathways for cardiovascular disease. Nat. Commun. 9, 3268 (2018).

20. Suhre, K. et al. Connecting genetic risk to disease end points through the human blood plasma proteome. Nat. Commun. 8, 14357 (2017).

21. COVID-19 Host Genetics Initiative. https://www.covid19hg.org/results/.

22. Erola Pairo-Castineira, Sara Clohisey, Lucija Klaric, Andrew Bretherick, Konrad Rawlik, Nicholas Parkinson, Dorota Pasko, Susan Walker, Anne Richmond, Max Head Fourman, Andy Law, James Furniss, Elvina Gountouna, Nicola Wrobel, Clark D Russell, Loukas Mout, J. K. B. Genetic mechanisms of critical illness in Covid-19. medrxiv (2020) doi:https://doi.org/10.1101/2020.09.24.20200048.

23. Staley, J. R. et al. PhenoScanner: a database of human genotype-phenotype associations. Bioinformatics 32, 3207-3209 (2016).

24. Kristiansen, H. et al. Extracellular 2'-5' Oligoadenylate Synthetase Stimulates RNase LIndependent Antiviral Activity: a Novel Mechanism of Virus-Induced Innate Immunity. J. Virol. 84, 11898-11904 (2010).

25. ATGen. https://nkmaxbio.com/sub/shop.php?ptype=view\&prdcode=2004011435.

26. Li, H. et al. Identification of a Sjögren's syndrome susceptibility locus at OAS1 that influences isoform switching, protein expression, and responsiveness to type I interferons. PLoS Genet. (2017) doi:10.1371/journal.pgen.1006820.

27. Prüfer, K. et al. A high-coverage Neandertal genome from Vindija Cave in Croatia. Science (80-. ). (2017) doi:10.1126/science.aao1887.

28. Meyer, M. et al. A high-coverage genome sequence from an archaic Denisovan individual. Science (80-. ). (2012) doi:10.1126/science.1224344.

29. Sams, A. J. et al. Adaptively introgressed Neandertal haplotype at the OAS locus functionally impacts innate immune responses in humans. Genome Biology (2016) doi:10.1186/s13059-016-1098-6.

30. Liu, X. et al. A functional variant in the OAS1 gene is associated with Sjögren's syndrome complicated with HBV infection. Sci. Rep. (2017) doi:10.1038/s41598-017-17931-9.

31. Li, Y. I. et al. Annotation-free quantification of RNA splicing using LeafCutter. Nat. Genet. (2018) doi:10.1038/s41588-017-0004-9.

32. Aguet, F. et al. The GTEx Consortium atlas of genetic regulatory effects across human tissues. Science (80-. ). (2020) doi:10.1126/SCIENCE.AAZ1776.

33. Aguet, F. et al. Genetic effects on gene expression across human tissues. Nature 550, 204-213 (2017).

34. Griffith, G. J. et al. Collider bias undermines our understanding of COVID-19 disease risk and severity. Nat. Commun. (2020) doi:10.1038/s41467-020-19478-2. 
35. Hornung, V., Hartmann, R., Ablasser, A. \& Hopfner, K. P. OAS proteins and cGAS: Unifying concepts in sensing and responding to cytosolic nucleic acids. Nat. Rev. Immunol. (2014) doi:10.1038/nri3719.

36. Mendez, F. L., Watkins, J. C. \& Hammer, M. F. Neandertal origin of genetic variation at the cluster of OAS immunity genes. Mol. Biol. Evol. (2013) doi:10.1093/molbev/mst004.

37. Bonnevie-Nielsen, V. et al. Variation in antiviral 2',5'-oligoadenylate synthetase (2'5'AS) enzyme activity is controlled by a single-nucleotide polymorphism at a splice-acceptor site in the OAS1 gene. Am. J. Hum. Genet. (2005) doi:10.1086/429391.

38. Hugo Zeberg, A. \& Pääbo, S. A genetic variant protective for COVID-19 is inherited from Neanderthals. bioRxiv (2020).

39. Carey, C. M. et al. Recurrent Loss-of-Function Mutations Reveal Costs to OAS1 Antiviral Activity in Primates. Cell Host Microbe (2019) doi:10.1016/j.chom.2019.01.001.

40. Zeberg, H. \& Pääbo, S. The major genetic risk factor for severe COVID-19 is inherited from Neanderthals. Nature (2020) doi:10.1038/s41586-020-2818-3.

41. Schneider, W. M., Chevillotte, M. D. \& Rice, C. M. Interferon-Stimulated Genes: A Complex Web of Host Defenses. Annu. Rev. Immunol. 32, 513-545 (2014).

42. Min, J.-Y. \& Krug, R. M. The primary function of RNA binding by the influenza A virus NS1 protein in infected cells: Inhibiting the 2'-5' oligo (A) synthetase/RNase L pathway. Proc. Natl. Acad. Sci. U. S. A. 103, 7100-7105 (2006).

43. $\mathrm{Hu}, \mathrm{B}$. et al. Cellular responses to HSV-1 infection are linked to specific types of alterations in the host transcriptome. Sci. Rep. 6, 28075 (2016).

44. Lim, J. K. et al. Genetic Variation in OAS1 Is a Risk Factor for Initial Infection with West Nile Virus in Man. PLoS Pathog. 5, e1000321 (2009).

45. Simon-Loriere, E. et al. High Anti-Dengue Virus Activity of the OAS Gene Family Is Associated With Increased Severity of Dengue. J. Infect. Dis. 212, 2011-2020 (2015).

46. Hamano, E. et al. Polymorphisms of interferon-inducible genes OAS-1 and MxA associated with SARS in the Vietnamese population. Biochem. Biophys. Res. Commun. 329, 1234-1239 (2005).

47. Di, H., Elbahesh, H. \& Brinton, M. A. Characteristics of human OAS1 isoform proteins. Viruses (2020) doi:10.3390/v12020152.

48. Cheng, G. et al. Pharmacologic Activation of the Innate Immune System to Prevent Respiratory Viral Infections. Am. J. Respir. Cell Mol. Biol. 45, 480-488 (2011).

49. Harari, D., Orr, I., Rotkopf, R., Baranzini, S. E. \& Schreiber, G. A robust type I interferon gene signature from blood RNA defines quantitative but not qualitative differences between three major IFN $\beta$ drugs in the treatment of multiple sclerosis. Hum. Mol. Genet. 24, 3192-3205 (2014).

50. Lin, F. ching \& Young, H. A. Interferons: Success in anti-viral immunotherapy. Cytokine and Growth Factor Reviews (2014) doi:10.1016/j.cytogfr.2014.07.015.

51. Arabi, Y. M. et al. Interferon Beta-1b and Lopinavir-Ritonavir for Middle East Respiratory Syndrome. N. Engl. J. Med. NEJMoa2015294 (2020) doi:10.1056/NEJMoa2015294. 
52. Pan, H. et al. Repurposed antiviral drugs for COVID-19 -interim WHO SOLIDARITY trial results. medRxiv 2020.10.15.20209817 (2020) doi:10.1101/2020.10.15.20209817.

53. Monk, P. D. et al. Safety and efficacy of inhaled nebulised interferon beta-1a (SNG001) for treatment of SARS-CoV-2 infection: a randomised, double-blind, placebo-controlled, phase 2 trial. Lancet Respir. Med. (2020) doi:10.1016/S2213-2600(20)30511-7.

54. Wood, E. R. et al. The role of phosphodiesterase 12 (PDE12) as a negative regulator of the innate immune response and the discovery of antiviral inhibitors. J. Biol. Chem. 290, 19681-19696 (2015).

55. Poulsen, J. B., Kjær, K. H., Justesen, J. \& Martensen, P. M. Enzyme assays for synthesis and degradation of 2-5As and other 2'-5' oligonucleotides. BMC Biochem. 16, 15 (2015).

56. Zhao, L. et al. Antagonism of the interferon-induced OAS-RNase L pathway by murine coronavirus ns2 protein is required for virus replication and liver pathology. Cell Host Microbe (2012) doi:10.1016/j.chom.2012.04.011.

57. Zhang, R. et al. Homologous 2',5'-phosphodiesterases from disparate RNA viruses antagonize antiviral innate immunity. Proc. Natl. Acad. Sci. U. S. A. (2013) doi:10.1073/pnas.1306917110.

58. Zhang, Q. et al. Inborn errors of type I IFN immunity in patients with life-threatening COVID-19. Science (80-. ). 5, eabd4570 (2020).

59. Verma, R. et al. A network map of Interleukin-10 signaling pathway. J. Cell Commun. Signal. (2016) doi:10.1007/s12079-015-0302-x.

60. Moreira-Teixeira, L. et al. T Cell-Derived IL-10 Impairs Host Resistance to Mycobacterium tuberculosis Infection . J. Immunol. (2017) doi:10.4049/jimmunol.1601340.

61. Kasten, K. R., Muenzer, J. T. \& Caldwell, C. C. Neutrophils are significant producers of IL-10 during sepsis. Biochem. Biophys. Res. Commun. (2010) doi:10.1016/j.bbrc.2010.01.066.

62. Lewkowicz, N. et al. Induction of human IL-10-producing neutrophils by LPS-stimulated Treg cells and IL-10. Mucosal Immunol. (2016) doi:10.1038/mi.2015.66.

63. Crepaldi, L. et al. Up-Regulation of IL-10R1 Expression Is Required to Render Human Neutrophils Fully Responsive to IL-10. J. Immunol. (2001) doi:10.4049/jimmunol.167.4.2312.

64. Iyer, S. S., Ghaffari, A. A. \& Cheng, G. Lipopolysaccharide-Mediated IL-10 Transcriptional Regulation Requires Sequential Induction of Type I IFNs and IL-27 in Macrophages. J. Immunol. (2010) doi:10.4049/jimmunol.1002041.

65. Ray, A., Chakraborty, K. \& Ray, P. Immunosuppressive MDSCS induced by TLR signaling during infection and role in resolution of inflammation. Frontiers in Cellular and Infection Microbiology (2013) doi:10.3389/fcimb.2013.00052.

66. Petruk, G. et al. SARS-CoV-2 Spike protein binds to bacterial lipopolysaccharide and boosts proinflammatory activity. bioRxiv (2020).

67. The crucial role of IL-10 in the anti-inflammatory effects of aerobic exercise in a model LPS-induced ARDS. Eur. Respir. J. (2013). 
medRxiv preprint doi: https://doi.org/10.1101/2020.10.13.20212092; this version posted December 24, 2020. The copyright holder for this preprint (which was not certified by peer review) is the author/funder, who has granted medRxiv a license to display the preprint in perpetuity.

It is made available under a CC-BY-NC-ND 4.0 International license .

68. Burgess, S., Davies, N. M. \& Thompson, S. G. Bias due to participant overlap in twosample Mendelian randomization. Genet. Epidemiol. 1-12 (2016) doi:10.1002/gepi.21998.

69. Hemani, G. et al. The MR-Base platform supports systematic causal inference across the human phenome. Elife 7, e34408 (2018).

70. Duration of Isolation and Precautions for Adults with COVID-19. https://www.cdc.gov/coronavirus/2019-ncov/hcp/duration-isolation.html.

71. Cevik, M. et al. SARS-CoV-2, SARS-CoV, and MERS-CoV viral load dynamics, duration of viral shedding, and infectiousness: a systematic review and meta-analysis. The Lancet Microbe (2020) doi:10.1016/s2666-5247(20)30172-5. 